\title{
Cell and tissue tropism of enterovirus 71 and other enteroviruses infections
}

Jing-Yi Lin ${ }^{1}$ and Shin-Ru Shih $2,3,4^{*}$

\begin{abstract}
Enterovirus 71 (EV71) is a member of Picornaviridae that causes mild and self-limiting hand, foot, and mouth disease (HFMD). However, EV71 infections can progress to polio-like paralysis, neurogenic pulmonary edema, and fatal encephalitis in infants and young children. Large EV71 outbreaks have been reported in Taiwan, China, Japan, Malaysia, Singapore, and Australia. This virus is considered a critical emerging public health threat. EV71 is an important crucial neurotropic enterovirus for which there is currently no effective antiviral drug or vaccine. The mechanism by which EV71 causes severe central nervous system complications remains unclear. The interaction between the virus and the host is vital for viral replication, virulence, and pathogenicity. SCARB2 or PSGL-1 receptor binding is the first step in the development of viral infections, and viral factors (e.g., 5' UTR, VP1, 3C, 3D, 3' UTR), host factors and environments (e.g., ITAFs, type I IFN) are also involved in viral infections. The tissue tropism and pathogenesis of viruses are determined by a combination of several factors. This review article provides a summary of host and virus factors affecting cell and tissue tropism and the pathogenesis of enteroviruses.
\end{abstract}

\section{Review}

\section{Introduction}

Enterovirus 71 (EV71), a member of the family Picornaviridae, poses a persistent global public health threat. EV71 infections typically cause hand, foot, and mouth disease (HFMD) or herpangina; however, EV71 has also been implicated as the etiological agent in several largescale outbreaks of severe neurological complications in children worldwide [1]. In recent years, an increase in EV71 activity has been noted throughout the Asia-Pacific region [2-6]. Severe neurological complications, including brainstem encephalitis, meningitis, poliomyelitis-like paralysis, and even death have occurred in this region. In 1998, an EV71 epidemic occurred in Taiwan, with the virus infecting over 120000 people and killing 78 children. Numerous small-scale EV71 epidemics have also occurred since 1998 in Taiwan [2].

EV71 is a positive-stranded RNA virus [7]. This viral RNA has a small protein named VPg covalently attached to its $5^{\prime}$ end and is polyadenylated at its $3^{\prime}$ terminus.

\footnotetext{
* Correspondence: srshih@mail.cgu.edu.tw

${ }^{2}$ Research Center for Emerging Viral Infections, Chang Gung University, Tao-Yuan, Taiwan

${ }^{3}$ Department of Medical Biotechnology and Laboratory Science, Chang Gung University, Tao-Yuan, Taiwan

Full list of author information is available at the end of the article
}

The genomic RNA is approximately 7500 nucleotides long. The $5^{\prime}$ untranslated region ( $5^{\prime}$ UTR) is 745 nucleotides long and highly structured, containing a cloverleaf-like structure that is integral for viral RNA synthesis and an internal ribosomal entry site (IRES) that is critical for the direction of viral mRNA translation. The cloverleaf-like structure at the $5^{\prime}$ end of this region is a multifunctional, cis-acting replication element that interacts with viral and cellular proteins to form a ribonucleoprotein complex. The approximately 450-nt IRES in the 5' UTR mediates the initiation of picornavirus translation. When the $40 \mathrm{~S}$ ribosomal subunit recognizes a sequence, RNA structure, or ribonucleoprotein complex within the IRES, initiation occurs at the authentic start codon. It has been reported that cellular proteins (such as poly $(\mathrm{C})$-binding protein 1 (PCBP1), poly $(\mathrm{C})$-binding protein 2 (PCBP2), polypyrimidine tract-binding protein (PTB), heterogeneous nuclear ribonucleoprotein A1 (hnRNP A1), heterogeneous nuclear ribonucleoprotein $\mathrm{K}$ (hnRNP K), La, upstream of N-ras (Unr), far upstream element binding protein 1 (FBP1), and far upstream element binding protein 2 (FBP2)) associate with the picornaviral 5' UTR and participate in either viral RNA replication or viral IRES activity, or both [8-14]. The viral RNA encodes a single large polyprotein, which undergoes several self-processing events that are mediated by virus-encoded proteases (2A and $3 \mathrm{C}$ ) to produce mature 
viral proteins (including 11 mature proteins and numerous partially processed products, depending on the virus). Four of these proteins (VP1-VP4) constitute the virus capsid, and the others participate in viral replication [15].

Pathogenesis is a multistep process: the virus-receptor interaction is the first step to initiating infection and the development of a disease is influenced by the intracellular milieu; induced cell functions, such as the capacity of the host to develop an effective immune response; the speed of virus replication; cytopathogenicity; and the spread of infection within and between tissues or organs, which might or might not depend on the presence of specific or different cellular receptors. This article reviews viral and host factors involved in the cell and tissue tropism of enteroviruses.

\section{Viral factors contribute to cell and tissue tropism}

EV71 serotypes are divided into 3 major genetic lineages: lineage $\mathrm{A}$ for which the prototype is the $\mathrm{BrCr}$ strain, and lineages $B$ and $C$, which are further subdivided into subgenogroups B1 to B5 and C1 to C5 $[3,16]$. Previous animal studies have shown that a mouse virulent strain of human EV71 belonging to subgenogroup B3 by serial passage is present in newborn BALB/c mice (MP-26 M). This virus strain expressing the VP1-G145E mutation increases viral growth and virulence in mice [17]. In the subgenogroup-B5 mouse-virulent EV71 strain, viruses expressing VP1-K244E mutation are critical genetic determinants of virulence [18]. Previous studies have reported that the $\mathrm{C} 1$ subgenogroup is rarely the cause of central nervous system (CNS) infections [3,4]; however, modifying a key mutation (Q145E) into capsid protein VP1 of the subgenogroup-C4 strain of EV71 generates a mouse-virulent EV71 strain [19].

Numerous studies have indicated that the $5^{\prime}$ UTR and 3' UTR of enteroviruses exert a considerable influence on tissue tropism, neurovirulence, and viral pathogenesis [20-23]. Nucleotides 480, 481, and 472 in the 5' UTR of PV are cited as neurovirulent determinants of PV1, 2, and 3 [24-26]. Stem-loop II within the 5' UTR of CVB1 and CVB3 determines the cardiovirulence phenotype [27]. In addition, nucleotide C158 in stem-loop II of the 5' UTR of unadapted isolated EV71 strain 237 contributes to virulence in mice [28].

Although previous studies in which animal models were used have succeeded in identifying genetic modifications that attenuate the virulence of enteroviruses, including coxsackieviruses, poliovirus, and EV71 [29-33], attempts to understand the underlying mechanism of virulence attenuation and the cell or tissue tropism of pathogenesis have not been assured.

Kok et al. reported that the modification of EV71 UTRs (5' UTR and 3' UTR) impairs growth in a cell-specific manner [34]. Replacing the entire EV71 5' UTR with that of human rhinovirus 2 (HRV2) resulted in a small reduction in growth efficiency in cells of both nonneuronal (rhabdomyosarcoma; RD) and neuronal (SH-SY5Y) origin because of reduced translation efficiency. However, introducing a 17-nucleotide deletion into the proximal region of the 3' UTR markedly reduced the growth of EV71-HRV2 in SH-SY5Y cells [34].

Cordey's group analyzed the genome of EV71 from various sites of infection in an immunocompromised host with disseminated disease. In vitro reverse genetics experiments in various EV71 lineages and in silico modeling data showed that the VP1 BC loop region of EV71 (L97R) plays a critical role in cell tropism independent of the EV71 lineage and, thus, might have contributed to dissemination and neurotropism in the immunocompromised patient [35].

\section{Host factors modulate cell and tissue tropism}

In addition to viral factors, several host factors are also involved in the cell and tissue tropism of enteroviruses.

\section{Receptors are the first step of viral infection}

Infection of cells by a cell-free virus and virus spread from cell to cell are different processes that might depend on the presence of different cellular surface molecules. In infected organs, cell-to-cell spread contributes substantially to the pathogenesis of a viral disease. When enteroviruses infect humans, they target numerous organs, causing gastrointestinal, myocardial, respiratory, and CNS diseases. Virus infection initiates after the viruses bind to a receptor on the cell surface; cellular receptors for viruses have been considered the primary determinants of cell and tissue tropism and pathogenicity. Recently, human scavenger receptor class B member 2 (hSCARB2) and P-selectin glycoprotein ligand-1 (PSGL-1) have been identified as receptors for EV71 [36,37]. In addition, EV71 uses SA-linked glycans as receptors for infection [38].

hSCARB2, which was originally identified as an EV71 receptor on RD cells, is expressed on a broad variety of cell types. Scavenger receptor class B, member 2 (also known as lysosomal integral membrane protein II, LGP85, and CD36b-like-2) is composed of 478 amino acids and belongs to the CD36 family. hSCARB2 is one of the most abundant proteins in the lysosomal membrane and participates in membrane transportation and the reorganization of the endosomal/lysosomal compartment. Several studies have suggested that hSCARB2 plays critical roles in efficient EV71 infection and the development of disease in humans [37,39]. EV71 binds to SCARB2 through a canyon of VP1 around residue Gln-172 for virus infection, and the entire exon 4 of SCARB2 is responsible for the interaction with the VP1 protein of EV71 [39,40]. In addition, Coxsackievirus A14 (CVA14) and Coxsackievirus A16 (CVA16), which are also major causative agents of HFMD, also use 
hSCARB2 as a receptor [37,41]. Coxsackievirus A7 (CVA7), which is occasionally associated with neurological diseases as well as EV71, also uses hSCARB2 for infection [41].

Enteroviruses must escape host immune system defenses to reach the CNS, and can cross the blood-brain barrier and become disseminated to the CNS from the bloodstream, infected leukocytes, or neural cells [42]. For poliovirus, CNS invasion is thought to occur through either the disruption of the blood-brain barrier or retrograde axonal transport [43]. In contrast, PSGL-1, which was first identified as an EV71 receptor on Jurkat T cells, is primarily expressed on leukocytes, where it mediates interaction with selectins and thus serves a crucial function in inflammatory processes [36]. Some EV71 strains bind to PSGL-1 and infect immune cells, but others do not. Nishimura et al. observed that EV71 binds to the PSGL-1 N-terminus, and that binding depends on tyrosine sulfation of the N-terminus [44]. They also observed that a single amino acid, residue 145 of the viral capsid protein (VP1-145), determines whether a virus binds to PSGL1 , and that it functions by influencing the orientation of a nearby lysine residue (VP1-244) on the virus surface. They proposed that VP1-145 controls virus tropism by changing the accessibility of the positivelycharged lysine side chain of VP1-244 to the negatively charged, sulfated N-terminus of PSGL-1. These results shed new light on virus-receptor interaction and EV71 tropism for PSGL-1-expressing leukocytes [45].

PSGL-1 is expressed mainly on leukocytes, but SCARB2 is widely expressed on various cell types, including neurons in the CNS. Moreover, unlike PSGL-1, SCARB2 can be used by most EV71 strains as an entry receptor [36,37]. Previous studies have reported that EV71 enters host cells through a mediated $\mathrm{pH}$ - and clathrin-dependent endocytosis pathway [46]. In addition, studies have reported that, to evaluate the role of SCARB2 and PSGL-1 during uncoating, the step of uncoating EV71 requires both SCARB2 and an acidic environment that forms after the virus-receptor complex is internalized into endosomes. However, this result was not observed in PSGL-1 [40,47]. Therefore, SCARB2 is capable of viral binding, viral internalization, and viral uncoating and greatly contributes to the early steps of EV71 infection [47].

\section{Other host factors}

The replication of many viruses is restricted to certain cells and tissues in the host. This tissue tropism results in a distinct disease pattern unique to each virus. Because virus infection initiates after viruses bind to a receptor on the cell surface, cellular receptors for viruses have been considered the primary determinants of tissue tropism. However, after identifying receptors for numerous viruses, it became apparent that receptor distribution in the host is wider than that in the virus replication sites [48].
This indicates that virus tropism might be determined by factors other than the virus receptor.

\section{Internal ribosomal entry site transactivating factors (ITAFs) are involved in viral translation}

The viral translation of enterovirus is IRES-dependent. IRES-mediated initiation might require both canonical initiation factors and IRES transactivating factors (ITAFs) that are not involved in cap-mediated initiation. ITAFs are cellular proteins that are not involved in normal cap-dependent translation but facilitate cap-independent translation. Different viral IRESs have different ITAF requirements, although several requirements are shared. ITAFs might serve as IRES chaperones, binding to RNA across multiple domains and stabilizing the entire IRES in a configuration that is appropriate for binding canonical translation factors, and ultimately ribosomes for translation. The ITAFs involved in enteroviruses replication and translation include PTB, nPTB, DRBP76, PCBP1, PCBP2, unr, La, hnRNP A1, hnRNP K, FBP1, and FBP2 [8-14,49]. However, some cellular factors, because of their cell and organ-specific distribution, might determine viral translation, propagation, virulence, and pathogenesis.

Mutations critical for the CNS attenuation of the Sabin vaccine strains of poliovirus are located within the viral IRES. The major determinant of neuroattenuation is a single-point mutation located within the viral IRES at nt 480,481 , or 472 in the cases of Sabin type 1 (Sabin1), Sabin2, and Sabin3, respectively [24-26]. A previous study showed that PTB and $\mathrm{nPTB}$ bind to a site directly adjacent to the nt 472 attenuating mutation, and binding at this site was less efficient on the Sabin3 IRES than on the PV3 IRES [23]. Translation mediated by the PV3 and Sabin3 IRESs in neurons of a chicken embryo spinal cord demonstrated a translation deficit for the Sabin3 IRES that could be rescued by increasing PTB expression in the CNS [23]. These data suggest that the low levels of PTB available in the CNS, as well as the reduced binding of PTB on the Sabin3 IRES, leads to its CNS-specific attenuation. Therefore, variable IRES trans activity of PTB and its neural isoform nPTB have been implicated in the neuroattenuation phenotype of the Sabin3 strain [23].

Some investigations have shown that doubled-stranded RNA-binding protein 76 (DRBP76) is associated with, and specifically repressed, the HRV2 IRES in neuronal but not in non-neuronal cells [49,50]. DRBP76 contains 2 dsRNA-binding motifs and is almost identical to M-phase phosphoprotein 4, NF90, translation control protein 80 (TCP80), and NF associated with dsRNA-1 (designated NFAR-1). Moreover, DRBP76 depletion in neuronal cells enhances rhinovirus IRES-driven translation and virus propagation [50]. 


\section{Interferon response controls tissue tropism and pathogenesis}

Picornaviruses are sensitive to IFNs, which play a central role in the innate immune antiviral response. The alpha/ beta interferon $($ IFN- $\alpha / \beta)$ response controls tissue tropism and the pathogenicity of poliovirus and coxsackievirus B3 (CVB3) [51,52]. AG129 mice lack alpha/beta interferon and IFN- $\gamma$ receptor genes and were initially generated to study the in vivo antiviral effects of IFN- $\alpha$ / $\beta$ and IFN- $\gamma$ [53]. When AG129 mice were infected with a non-mouse-adapted strain of EV71 (5865/SIN/00009), the virus exhibited neurotropism and caused neurological damage that was likely responsible for the limb paralysis observed in the infected AG129 mice [54].

Enteroviruses may enter the CNS through the bloodbrain barrier (BBB) or through axonal transport from the periphery. The host systemic adaptive and CNS innate immune systems express pattern-recognition receptors (PRRs) (endosomal Toll-like receptors (TLRs), cytoplasmic retinoic acid-inducible gene 1 (RIG-1), and melanoma differentiation-associated gene 5 (MDA-5)), which detect viral nucleic acids and initiate host antiviral responses. MDA-5 is a crucial factor for EV71 RNAactivated type I IFN expression [55]. However, EV71 inhibits the type I IFN response mediated by RIG-1 and TLR3, and this process involves the $3 \mathrm{C}$ viral protease that cleaves interferon regulatory factor 7 (IRF7) [56-58]. In addition, EV71 viral $3 \mathrm{C}$ protease inhibits the host cell antivirus type I IFN response promoting virus replication in mice [59].

\section{Roles of microRNAs in the interaction network between virus and host}

In addition to host proteins and viral genome diversity, some small RNAs have been reported to be involved in regulating viral replication and translation in viral life cycles [60-63]. MicroRNAs (miRNAs) are a recently discovered class of RNAs with the function of posttranscriptional gene expression regulation. It has been demonstrated that miRNAs play crucial roles in the complex interaction network between a virus and a host [64]. miRNA expression is tissue dependent and the abundance of a particular miRNA might present a clue regarding whether it functions in the tissue [65]. Group B coxsackieviruses (CVBs) are the human enterovirus B species of the Picornaviridae family. They are divided into 6 serotypes (CVB1-6) and are the major pathogens of human viral myocarditis that can lead to dilated cardiomyopathy and cardiac failure [66]. Zhong's group determined that miR-342-5p could suppress CVB3 biogenesis by targeting its $2 \mathrm{C}$-coding sequence [67]. They also observed that miR-10a* upregulated CVB3 biosynthesis by targeting the $3 \mathrm{D}$-coding sequence. MiR10a* was detectable in the cardiac tissue of suckling Balb/c mice, suggesting that miR10a* might affect CVB3 replication during its cardiac infection [61].

\section{Conclusion}

During viral life cycle, enteroviruses use viral factors and multiple host factors to mediate crucial reactions during their life cycle, including receptor binding, IRES-mediated translation, viral RNA replication, and viral assembly. However, tissue-specific viral virulence remains unclear from cell-based system to animal model, and requires further investigation in the future. Small RNAs encoded by viruses or hosts might play vital roles in complex signaling pathways of the virushost interaction network; this is also a critical process requiring further investigation.

\section{Competing interests}

The authors declare that they have no competing interests.

\section{Authors' contributions}

JYL wrote the manuscript; SRS critically revised the manuscript. Both authors have read and approved the final manuscript.

\section{Acknowledgements}

The authors would like to thank the National Science Council of the Republic of China, Taiwan, for financially supporting this research under Contract No. NSC-101-2325-B-182-015 and also thanks Chang Gung Memorial Hospital for supporting this study under Contract No. CMRPD1A0672. We also thanks for the Center of Infectious Disease and Signaling Research, National Cheng Kung University. Vincent Katona is appreciated for his editorial assistance.

\section{Author details}

${ }^{1}$ School of Medical Laboratory Science and Biotechnology, College of Medical Science and Technology, Taipei Medical University, Taipei, Taiwan. ${ }^{2}$ Research Center for Emerging Viral Infections, Chang Gung University, Tao-Yuan, Taiwan. ${ }^{3}$ Department of Medical Biotechnology and Laboratory Science, Chang Gung University, Tao-Yuan, Taiwan. ${ }^{4}$ Clinical Virology Laboratory, Chang Gung Memorial Hospital, Tao-Yuan, Taiwan.

Received: 30 November 2013 Accepted: 26 February 2014 Published: 7 March 2014

\section{References}

1. Alexander JP Jr, Baden L, Pallansch MA, Anderson LJ: Enterovirus 71 infections and neurologic disease-United States, 1977-1991. J Infect Dis 1994, 169:905-908.

2. Ho M, Chen ER, Hsu KH, Twu SJ, Chen KT, Tsai SF, Wang JR, Shih SR: An epidemic of enterovirus 71 infection in Taiwan. Taiwan enterovirus epidemic working group. N Engl J Med 1999, 341:929-935.

3. McMinn P, Lindsay K, Perera D, Chan HM, Chan KP, Cardosa MJ: Phylogenetic analysis of enterovirus 71 strains isolated during linked epidemics in Malaysia, Singapore, and Western Australia. J Virol 2001, 75:7732-7738

4. McMinn PC: An overview of the evolution of enterovirus 71 and its clinical and public health significance. FEMS Microbiol Rev 2002, 26:91-107.

5. Shimizu H, Utama A, Yoshii K, Yoshida H, Yoneyama T, Sinniah M, Yusof MA, Okuno Y, Okabe N, Shih SR, Chen HY, Wang GR, Kao CL, Chang KS, Miyamura T, Hagiwara A: Enterovirus 71 from fatal and nonfatal cases of hand, foot and mouth disease epidemics in Malaysia, Japan and Taiwan in 1997-1998. Jpn J Infect Dis 1999, 52:12-15.

6. Yang F, Ren L, Xiong Z, Li J, Xiao Y, Zhao R, He Y, Bu G, Zhou S, Wang J, Qi J: Enterovirus 71 outbreak in the People's Republic of China in 2008. J Clin Microbiol 2009, 47:2351-2352.

7. Brown BA, Pallansch MA: Complete nucleotide sequence of enterovirus 71 is distinct from poliovirus. Virus Res 1995, 39:195-205.

8. Huang PN, Lin JY, Locker N, Kung YA, Hung CT, Lin JY, Huang HI, Li ML, Shih SR: Far upstream element binding protein 1 binds the internal 
ribosomal entry site of enterovirus 71 and enhances viral translation and viral growth. Nucleic Acids Res 2011, 39:9633-9648.

9. Lin JY, Chen TC, Weng KF, Chang SC, Chen LL, Shih SR: Viral and host proteins involved in picornavirus life cycle. J Biomed Sci 2009, 16:103.

10. Lin JY, Li ML, Huang PN, Chien KY, Horng JT, Shih SR: Heterogeneous nuclear ribonuclear protein $\mathrm{K}$ interacts with the enterovirus $715^{\prime}$ untranslated region and participates in virus replication. J Gen Virol 2008, 89:2540-2549.

11. Lin JY, Li ML, Shih SR: Far upstream element binding protein 2 interacts with enterovirus 71 internal ribosomal entry site and negatively regulates viral translation. Nucleic Acids Res 2009, 37:47-59.

12. Lin JY, Shih SR, Pan M, Li C, Lue CF, Stollar V, Li ML: hnRNP A1 interacts with the $5^{\prime}$ untranslated regions of enterovirus 71 and Sindbis virus RNA and is required for viral replication. J Virol 2009, 83:6106-6114.

13. Shih SR, Stollar V, Li ML: Host factors in enterovirus 71 replication. J Virol 2011, 85:9658-9666.

14. Huang HI, Weng KF, Shih SR: Viral and host factors that contribute to pathogenicity of enterovirus 71. Future Microbiol 2012, 7:467-479.

15. Stanway G: Structure, function and evolution of picornaviruses. J Gen Virol 1990, 71(Pt 11):2483-2501.

16. Brown BA, Oberste MS, Alexander JP Jr, Kennett ML, Pallansch MA Molecular epidemiology and evolution of enterovirus 71 strains isolated from 1970 to 1998. J Virol 1999, 73:9969-9975.

17. Chua BH, Phuektes P, Sanders SA, Nicholls PK, McMinn PC: The molecular basis of mouse adaptation by human enterovirus 71. J Gen Virol 2008, 89:1622-1632

18. Zaini Z, Phuektes P, McMinn P: Mouse adaptation of a sub-genogroup B5 strain of human enterovirus 71 is associated with a novel lysine to glutamic acid substitution at position 244 in protein VP1. Virus Res 2012, 167:86-96.

19. Zaini Z, McMinn P: A single mutation in capsid protein VP1 (Q145E) of a genogroup C4 strain of human enterovirus 71 generates a mousevirulent phenotype. J Gen Virol 1935-1940, 2012:93.

20. Merkle I, van Ooij MJ, van Kuppeveld FJ, Glaudemans DH, Galama JM, Henke A, Zell R, Melchers WJ: Biological significance of a human enterovirus B-specific RNA element in the 3' nontranslated region. J Virol 2002, 76:9900-9909.

21. Dunn JJ, Chapman NM, Tracy S, Romero JR: Genomic determinants of cardiovirulence in coxsackievirus B3 clinical isolates: localization to the $5^{\prime}$ nontranslated region. J Virol 2000, 74:4787-4794.

22. Gromeier M, Alexander L, Wimmer E: Internal ribosomal entry site substitution eliminates neurovirulence in intergeneric poliovirus recombinants. Proc Natl Acad Sci U S A 1996, 93:2370-2375

23. Guest S, Pilipenko E, Sharma K, Chumakov K, Roos RP: Molecular mechanisms of attenuation of the Sabin strain of poliovirus type 3 . J Virol 2004, 78:11097-11107.

24. Kawamura N, Kohara M, Abe S, Komatsu T, Tago K, Arita M, Nomoto A Determinants in the $5^{\prime}$ noncoding region of poliovirus Sabin 1 RNA that influence the attenuation phenotype. J Virol 1989, 63:1302-1309.

25. Moss EG, O'Neill RE, Racaniello VR: Mapping of attenuating sequences of an avirulent poliovirus type 2 strain. J Virol 1884-1890, 1989:63.

26. Westrop GD, Wareham KA, Evans DM, Dunn G, Minor PD, Magrath DI, Taffs F, Marsden S, Skinner MA, Schild GC, Almond JW: Genetic basis of attenuation of the Sabin type 3 oral poliovirus vaccine. J Virol 1989, 63:1338-1344

27. Dunn JJ, Bradrick SS, Chapman NM, Tracy SM, Romero JR: The stem loop II within the 5 ' nontranslated region of clinical coxsackievirus B3 genomes determines cardiovirulence phenotype in a murine model. J Infect Dis 2003, 187:1552-1561

28. Yeh MT, Wang SW, Yu CK, Lin KH, Lei HY, Su IJ, Wang JR: A single nucleotide in stem loop II of $5^{\prime}$-untranslated region contributes to virulence of enterovirus 71 in mice. PLoS One 2011, 6:e27082.

29. Campbell SA, Lin J, Dobrikova EY, Gromeier M: Genetic determinants of cell type-specific poliovirus propagation in HEK 293 cells. J Virol 2005, 79:6281-6290.

30. Dobrikova E, Florez P, Bradrick S, Gromeier M: Activity of a type 1 picornavirus internal ribosomal entry site is determined by sequences within the $3^{\prime}$ nontranslated region. Proc Natl Acad Sci U S A 2003, 100:15125-15130.

31. Arita M, Shimizu H, Nagata N, Ami Y, Suzaki Y, Sata T, Iwasaki T, Miyamura T: Temperature-sensitive mutants of enterovirus 71 show attenuation in cynomolgus monkeys. J Gen Virol 2005, 86:1391-1401.
32. Arita M, Nagata N, Iwata N, Ami Y, Suzaki $Y$, Mizuta K, Iwasaki T, Sata T, Wakita T, Shimizu $\mathrm{H}$ : An attenuated strain of enterovirus 71 belonging to genotype a showed a broad spectrum of antigenicity with attenuated neurovirulence in cynomolgus monkeys. J Virol 2007, 81:9386-9395.

33. Arita M, Ami Y, Wakita T, Shimizu H: Cooperative effect of the attenuation determinants derived from poliovirus sabin 1 strain is essential for attenuation of enterovirus 71 in the NOD/SCID mouse infection model. J Virol 2008, 82:1787-1797.

34. Kok CC, Phuektes P, Bek E, McMinn PC: Modification of the untranslated regions of human enterovirus 71 impairs growth in a cell-specific manner. J Virol 2012, 86:542-552.

35. Cordey S, Petty TJ, Schibler M, Martinez Y, Gerlach D, van Belle S, Turin L, Zdobnov E, Kaiser L, Tapparel C: Identification of site-specific adaptations conferring increased neural cell tropism during human enterovirus 71 infection. PLOS Pathog 2012, 8:e1002826.

36. Nishimura Y, Shimojima M, Tano Y, Miyamura T, Wakita T, Shimizu H: Human P-selectin glycoprotein ligand-1 is a functional receptor for enterovirus 71. Nat Med 2009, 15:794-797.

37. Yamayoshi S, Yamashita Y, Li J, Hanagata N, Minowa T, Takemura T, Koike S: Scavenger receptor B2 is a cellular receptor for enterovirus 71. Nat Med 2009, 15:798-801.

38. Yang $B$, Chuang $H$, Yang KD: Sialylated glycans as receptor and inhibitor of enterovirus 71 infection to DLD-1 intestinal cells. Virol J 2009, 6:141.

39. Yamayoshi S, Koike S: Identification of a human SCARB2 region that is important for enterovirus 71 binding and infection. J Virol 2011 85:4937-4946

40. Chen P, Song Z, Qi Y, Feng X, Xu N, Sun Y, Wu X, Yao X, Mao Q, Li X, Dong W, Wan X, Huang N, Shen X, Liang Z, Li W: Molecular determinants of enterovirus 71 viral entry: cleft around GLN-172 on VP1 protein interacts with variable region on scavenge receptor B 2. J Biol Chem 2012, 287:6406-6420.

41. Yamayoshi S, lizuka S, Yamashita T, Minagawa H, Mizuta K, Okamoto M Nishimura H, Sanjoh K, Katsushima N, Itagaki T, Nagai Y, Fujii K, Koike S: Human SCARB2-dependent infection by coxsackievirus A7, A14, and A16 and enterovirus 71. J Virol 2012, 86:5686-5696.

42. Feuer $R$, Mena I, Pagarigan RR, Harkins S, Hassett DE, Whitton JL: Coxsackievirus B3 and the neonatal CNS: the roles of stem cells, developing neurons, and apoptosis in infection, viral dissemination, and disease. Am J Pathol 2003, 163:1379-1393.

43. Solomon T, Lewthwaite P, Perera D, Cardosa MJ, McMinn P, Ooi MH: Virology, epidemiology, pathogenesis, and control of enterovirus 71. Lancet Infect Dis 2010, 10:778-790.

44. Nishimura Y, Wakita T, Shimizu H: Tyrosine sulfation of the amino terminus of PSGL-1 is critical for enterovirus 71 infection. PLoS Pathog 2010, 6:e1001174.

45. Nishimura Y, Lee H, Hafenstein S, Kataoka C, Wakita T, Bergelson JM, Shimizu H: Enterovirus 71 binding to PSGL-1 on leukocytes: VP1-145 acts as a molecular switch to control receptor interaction. PLoS Pathog 2013, 9:e1003511.

46. Hussain $\mathrm{KM}$, Leong $\mathrm{KL}, \mathrm{Ng} \mathrm{MM}$, Chu JJ: The essential role of clathrin-mediated endocytosis in the infectious entry of human enterovirus 71. J Biol Chem 2011, 286:309-321.

47. Yamayoshi S, Ohka S, Fujii K, Koike S: Functional comparison of SCARB2 and PSGL1 as receptors for enterovirus 71. J Virol 2013, 87:3335-3347.

48. Schneider-Schaulies J: Cellular receptors for viruses: links to tropism and pathogenesis. J Gen Virol 2000, 81:1413-1429.

49. Merrill MK, Dobrikova EY, Gromeier M: Cell-type-specific repression of internal ribosome entry site activity by double-stranded RNA-binding protein 76. J Virol 2006, 80:3147-3156.

50. Merrill MK, Gromeier M: The double-stranded RNA binding protein 76: NF45 heterodimer inhibits translation initiation at the rhinovirus type 2 internal ribosome entry site. J Virol 2006, 80:6936-6942.

51. Ida-Hosonuma M, Iwasaki T, Yoshikawa T, Nagata N, Sato Y, Sata T, Yoneyama M, Fujita T, Taya C, Yonekawa H, Koike S: The alpha/beta interferon response controls tissue tropism and pathogenicity of poliovirus. J Virol 2005, 79:4460-4469.

52. Wessely R, Klingel K, Knowlton KU, Kandolf R: Cardioselective infection with coxsackievirus B3 requires intact type I interferon signaling: implications for mortality and early viral replication. Circulation 2001, 103:756-761.

53. van den Broek MF, Muller U, Huang S, Aguet M, Zinkernagel RM: Antiviral defense in mice lacking both alpha/beta and gamma interferon receptors. J Virol 1995, 69:4792-4796. 
54. Khong WX, Yan B, Yeo H, Tan EL, Lee JJ, Ng JK, Chow VT, Alonso S: A non-mouse-adapted enterovirus 71 (EV71) strain exhibits neurotropism, causing neurological manifestations in a novel mouse model of EV71 infection. J Virol 2012, 86:2121-2131.

55. Kuo RL, Kao LT, Lin SJ, Wang RY, Shih SR: MDA5 plays a crucial role in enterovirus 71 RNA-mediated IRF3 activation. PLoS One 2013, 8:e63431.

56. Lei X, Xiao X, Xue Q, Jin Q, He B, Wang J: Cleavage of interferon regulatory factor 7 by enterovirus $713 C$ suppresses cellular responses. J Virol 2013, 87:1690-1698.

57. Lei X, Sun Z, Liu X, Jin Q, He B, Wang J: Cleavage of the adaptor protein TRIF by enterovirus $713 C$ inhibits antiviral responses mediated by Toll-like receptor 3. J Virol 2011, 85:8811-8818.

58. Lei X, Liu X, Ma Y, Sun Z, Yang Y, Jin Q, He B, Wang J: The 3 C protein of enterovirus 71 inhibits retinoid acid-inducible gene I-mediated interferon regulatory factor 3 activation and type I interferon responses. J Virol 2010, 84:8051-8061.

59. Lee YP, Wang YF, Wang JR, Huang SW, Yu CK: Enterovirus 71 blocks selectively type I interferon production through the $3 \mathrm{C}$ viral protein in mice. J Med Virol 2012, 84:1779-1789.

60. Kelly E, Hadac EM, Greiner S, Russell SJ: Engineering microRNA responsiveness to decrease virus pathogenicity. Nat Med 2008, 14:1278-1283.

61. Tong L, Lin L, Wu S, Guo Z, Wang T, Qin Y, Wang R, Zhong X, Wu X, Wang Y, Luan T, Wang Q, Li Y, Chen X, Zhang F, Zhao W, Zhong Z: MiR-10a* up-regulates coxsackievirus $\mathrm{B} 3$ biosynthesis by targeting the $3 \mathrm{D}$-coding sequence. Nucleic Acids Res 2013, 41:3760-3771.

62. Wen BP, Dai HJ, Yang YH, Zhuang Y, Sheng R: MicroRNA-23b inhibits enterovirus 71 replication through downregulation of EV71 VPI protein. Intervirology 2013, 56:195-200.

63. Zheng Z, Ke X, Wang M, He S, Li Q, Zheng C, Zhang Z, Liu Y, Wang H: Human microRNA hsa-miR-296-5p suppresses enterovirus 71 replication by targeting the viral genome. J Virol 2013, 87:5645-5656.

64. Gottwein E: Roles of microRNAs in the life cycles of mammalian viruses. Curr Top Microbiol Immunol 2013, 371:201-227.

65. Ro S, Park C, Young D, Sanders KM, Yan W: Tissue-dependent paired expression of miRNAs. Nucleic Acids Res 2007, 35:5944-5953.

66. Knowlton KU: CVB infection and mechanisms of viral cardiomyopathy. Curr Top Microbiol Immunol 2008, 323:315-335.

67. Wang $L$, Qin $Y$, Tong $L$, Wu S, Wang Q, Jiao Q, Guo Z, Lin L, Wang R, Zhao W, Zhong Z: MiR-342-5p suppresses coxsackievirus B3 biosynthesis by targeting the 2C-coding region. Antiviral Res 2012, 93:270-279.

doi:10.1186/1423-0127-21-18

Cite this article as: Lin and Shih: Cell and tissue tropism of enterovirus

71 and other enteroviruses infections. Journal of Biomedical Science

2014 21:18.

\section{Submit your next manuscript to BioMed Central and take full advantage of:}

- Convenient online submission

- Thorough peer review

- No space constraints or color figure charges

- Immediate publication on acceptance

- Inclusion in PubMed, CAS, Scopus and Google Scholar

- Research which is freely available for redistribution 